\title{
Crystallisation of polypropylene matrix in composites filled with wooden parts of rapeseed straw
}

\author{
Dominik Paukszta • Justyna Zielińska-Maćkowiak
}

Bretsznajder Special Chapter

(C) The Author(s) 2012. This article is published with open access at Springerlink.com

\begin{abstract}
Nucleation ability of native and modified rapeseed straw during the polypropylene crystallization from the melt was investigated by the DSC method. Composites were made from isotactic polypropylene and lignocellulosic material using extrusion and injection moulding techniques. They were obtained using polypropylenes differing with respect to melt flow rates and different varieties of rapeseed straw. Chemical modification was carried out in two stages: through mercerisation and treatment with acetic acid anhydride. In the course of investigations, it was found that both native and modified rapeseed straw acted as an active nucleant of polypropylene crystallisation characterised by low values of MFR indices. It was found that for polypropylenes with high MFR values, the values of crystallization temperatures and crystallization half-time in composites were identical when compared with non-filled polymers. The investigations demonstrated that there were insignificant differences among composites containing straw from different varieties of rapeseed. The analysis of crystallization temperatures confirmed that rapeseed straw modification failed to change this parameter of the crystallization process. A similar tendency was observed in the case of changes of the half-time crystallization process. Moreover, the analysis of the crystallization temperature and crystallization half-time showed that the presence in composites of lignified rapeseed straw particles played an important role in the crystallization conditions.
\end{abstract}

D. Paukszta $(\square) \cdot J$. Zielińska-Maćkowiak Institute of Chemical Technology and Engineering, Poznan University of Technology, M. Sklodowskiej-Curie 2, 60-695 Poznan, Poland

e-mail: Dominik.Paukszta@put.poznan.pl
Keywords Polypropylene - Composites · Rapeseed straw · Chemical modification $\cdot$ Crystallization $\cdot$ DSC method

\section{Introduction}

The composites with natural lignocellulosic materials like natural fibres, shivers, straws and wood have recently been intensively investigated due to favourable mechanical properties of such materials and their ecological aspects [1-6]. New composites are manufactured with rapeseed straw [7, 8].

Our earlier experiments revealed that mechanical properties of polypropylene composites filled with comminuted pine and oak wood as well as composites containing rapeseed straw were similar [9]. In this study, we found that the composites with wood or rapeseed straw were characterised by very similar values, e.g. elongation at break and hardness. For example, for the propylene composite (Malen F-401) with $30 \%$ of modified rapeseed straw (Kaszub variety), the tensile strength was $26.3 \mathrm{MPa}$, elongation at break $6.2 \%$ and hardness $58.0 \mathrm{~N} / \mathrm{mm}^{2}$ [9].

World crops of rapeseed are estimated at over 50 million tons. So far, no method has been developed which would allow wide exploitation of rape straw as a waste material. This lignocellulosic material is suitable for manufacturing composites with isotactic polypropylene as their matrix. Presently, polyolefin composites reinforced with wood or natural fibres are used in furniture, building and automotive industries.

Application of renewable resources, partial biodegradability and positive mechanical properties of polypropylene composites containing lignocellulosic materials constitute an essential motive for conducting fundamental investigations of such materials. 
Properties of composites are affected, to a considerable extent, by their structure as well as by interactions between the filler and the matrix. From the point of view of industrial processing of polymers, it is essential to recognise phenomena of crystallisation in non-isothermal conditions. Investigations carried out with the assistance of the DSC technique make it possible to combine phenomena taking place during the process of crystallisation of the composite polymer matrix with the macroscopic properties of the materials.

The nucleating effect resulting in the increase of polypropylene crystalline structures can be attributed to many factors. Experiments on the impact of the phenomenon of additive nucleation on polyolefin structures, in particular of polypropylene, were carried out many years ago by Binsbergen $[10,11]$ who examined over two thousand compounds and divided active nucleants into six inorganic and organic groups. However, lignocellulosic materials were not investigated. Frequently, the nucleation phenomenon is closely correlated with the phenomenon of epitaxy as evidenced by the pioneering studies of Chatterjee et al. [12-14]. Investigations on the effect of talc used not only as filler but, primarily, as a nucleant of the crystallisation process were carried out by Mencel and Varga [15]. They found that, together with the increase of talc content in the composite, also the crystallisation temperature of the polypropylene matrix increased. Experiments on the nucleation effect of inorganic compounds are continued. Bogoeva-Gaceva et al. [16] found that depending on the type of surface treatment, glass fibres were shown to exhibit different nucleating effects.

Nucleating efficiency of various inorganic and organic fillers of isotactic polypropylene, for example: talc, kaolin, chalk, nano-clay particles and chitosan were investigated $[17,18]$. The best nucleating agents turned out to be talc and carbon black.

In view of the observed increasing interest in research work as well as growing industrial production of polymer composites filled with renewable biomaterials, it is important to investigate the impact of lignocellulosic fillers on the structural constitution of the polymer matrix and, subsequently, on functional properties of these composites. In addition, the analysis of the influence of the modification of the filler or of the polymer matrix is also important. The applied modification requires introduction of additional technological operations and is expensive but it significantly improves properties of composites. That is why composites with modified and non-modified fillers are subjected to investigations and manufactured on an industrial scale.

A comprehensive literature review of the nucleation capability phenomena of wood fillers for non-isothermal crystallisation of polypropylene was presented by Borysiak $[19,20]$ and Bouza et al. [20, 21]. In their experiments, they also investigated the influence of wood earlier subjected to chemical modification. It was found that compatibilization evidently affects the reduction of the crystallization temperature of polypropylene. On the other hand, Borysiak [19] found that the different nucleating activity for lignocellulosic fillers was evaluated by crystal conversion, half-time of crystallization and crystallization temperature and that the chemically modified wood filler caused reduction in the nucleation efficiency of polypropylene. Many modification methods of lignocellulosic materials are available [23], although the most commonly applied one is modification with the assistance of acetic acid anhydride and that is why it will be used in these experiments.

Other studies discuss nucleation influence of other lignocellulosic materials, primarily, natural fibres. For example, by using short sisal fibres, an increase in the crystallisation temperature and crystallinity upon the addition of fibres to the polypropylene matrix was achieved [24].

Another observation is the fact of development of a beta form of isotactic polypropylene in composites with lignocellulosic materials. Numerous researchers maintain that the cause of development of another polymorphic form is the occurrence of shearing forces induced by the presence of wood or fibre particles in conditions of processing $[9,19,25]$ as well as rapid cooling during the injection moulding cycle [21]. Joseph et al. [24] used polypropylene modified with a specific nucleation agent which promotes crystallization in the $\beta$-phase.

Until this time, no investigations were carried out on the impact of filler in the form of lignified tissue derived from comminuted rapeseed straw on the crystallisation process of a polypropylene matrix. Polypropylene, like other polymers, is manufactured in different kinds differing, among others, in their rheological properties determined by the melt flow rate (MFR) index. It appears interesting to investigate how the process of matrix nucleation against the same lignocellulosic material will affect matrix diversification in the case of considerably varying MFR index.

The main aim of this study was to investigate nucleation of rapeseed straw on polypropylene matrix as well as the influence of chemical modification of lignocellulosic materials in composites, using DSC method. In other words, the aim relates to use of a new filler in the form of rapeseed straw, which effects utility of the composites.

\section{Experimental}

\section{Materials}

Commercial isotactic polypropylenes Malen P F-401 (PP1), Malen P S-702 (PP2), Moplen HP-548R (PP3) and 
Moplen HP-648T (PP4) produced by PKN Orlen (Poland) were used in this study. They were characterised by the following MFR indices: $2.4-3.2 \mathrm{~g} / 10 \mathrm{~min}$ for Malen F-401, 11-16 g/10 min for Malen P S-702, $25 \mathrm{~g} / 10 \mathrm{~min}$ Moplen HP-548R and $50 \mathrm{~g} / 10 \mathrm{~min}$ for Moplen HP-648T. Despite differing rheological properties, all the above propylenes are intended for formatting using the moulding injection method. They can also be employed for filling to obtain composites.

Lignocellulosic materials derived from various winter oilseed rape varieties were used to manufacture experimental composites. Rape straw for trials was collected from experimental plots of the Plant Breeding and Acclimatization Institute-National Research Institute in Poznan.

For experiments on the nucleation of native rape straw, equal proportions of the following eleven different rape varieties were employed: Lisek, Kaszub, Pomorzanin, Californium, Carina, Buffallo, Bazyl, Bosman, Mazur, Kana and Marita. In this series of trials, composites were designated as follows: C1 (with PP1), C2 (with PP2), C3 (with PP3) and C4 (with PP4).

For comparative studies to examine the effect of nonmodified and modified lignocellulosic materials, rape straw of the following four rape seed varieties were used: Bojan, Californium, Kaszub and Lisek. The composite filled with rape straw of the Bojan variety was designated as Composite (CI), the one filled with Californium rape straw-as Composite II (CII), the one filled with Kaszub rape strawas Composite III (CIII) and the one filled with Lisek rape straw-as Composite IV (CIV).

\section{Chemical treatment of rapeseed straw}

The method used to improve the adhesion between natural fillers and polyolefin polymers was chemical modification of natural lignocellulosic materials.

The above-mentioned four varieties of rape straw were subjected to chemical modification. Following comminution and separation of the parenchymal tissue, the lignocellulosic material was mercerised at $20 \%$ hydroxide sodium solution. After bringing straw to neutral reaction and drying it to constant mass, the material was subjected to modification in order to improve its adhesion to nonpolar polyolefin matrix. Mercerized rapeseed straw was immersed in acetic anhydride/xylene mixture. The content of acetic anhydride was $300 \%$ (wt) in proportion to the filler mass. The time of treatment was $120 \mathrm{~min}$ at temperature $120{ }^{\circ} \mathrm{C}$. After reactions the lignocellulosic materials were washed three times with ethanol to remove acetic anhydride. Then the straw was dried at room temperature until constant weight was achieved.
Preparation of composites

The samples were made by extrusion and, subsequently, by the injection moulding method. The obtained products contained 25 and $30 \%$ by mass of the lignocellulosic filler. During the injection process, moulds allowing the formation of standard moulded pieces measuring $150 \mathrm{~m} / 10 \mathrm{~mm} /$ $4 \mathrm{~mm}$. The temperature in the heating zones in the course of the above-mentioned formation processes did not exceed $200{ }^{\circ} \mathrm{C}$ to prevent thermal destruction of the lignocellulosic constituent.

\section{DSC measurements}

Two types of polypropylene composites filled with rapeseed straw were used in the experiments: (a) nativewithout any previous chemical treatment, (b) after chemical modification improving the adhesion between polypropylene and rapeseed straw.

Thermal analysis was performed using a Netzsch Differential Scanning Calorimeter, model DSC 200, under argon atmosphere. The DSC equipment was calibrated with indium standard $\left(T_{\mathrm{m}}=156.6{ }^{\circ} \mathrm{C}, \Delta H_{\mathrm{m}}=28.45 \mathrm{~kJ} / \mathrm{kg}\right)$ for temperature and enthalpy changes. For non-isothermal crystallization investigations, the samples were heated to $200{ }^{\circ} \mathrm{C}$ (at a heating rate of $10{ }^{\circ} \mathrm{C} / \mathrm{min}$ ) and kept at this temperature for $2 \mathrm{~min}$ to eliminate the previous thermal and/or mechanical history. Then, the samples were quenched to $40{ }^{\circ} \mathrm{C}$ at the rate of $5{ }^{\circ} \mathrm{C} / \mathrm{min}$ (using argon flow). The investigations were carried out in neutral (argon) atmosphere. This procedure was repeated two times. The objective of these experiments was to check how the repeated process of sample crystallisation in the DSC apparatus affected basic composite parameters in comparison with the unfilled isotactic polypropylene. The temperature program is given in Table 1.

On the basis of the performed DSC measurements, the following parameters were determined: crystallisation

Table 1 Temperature program used in DSC study

\begin{tabular}{llll}
\hline $\mathrm{Nr}$ & $\begin{array}{l}\text { Successive } \\
\text { segments }\end{array}$ & Temperature & $\begin{array}{l}\text { Speed of } \\
\text { heating/cooling }\end{array}$ \\
\hline 0 & "Initiation" & $40^{\circ}$ & - \\
1 & "Dynamic" & $40-200{ }^{\circ} \mathrm{C}$ (heating) & $10 \mathrm{~K} / \mathrm{min}$ \\
2 & "Isothermal" & $200{ }^{\circ} \mathrm{C}$ & - \\
3 & "Dynamic" & $200-40{ }^{\circ} \mathrm{C}$ (cooling) & $5 \mathrm{~K} / \mathrm{min}$ \\
4 & "Isothermal" & $40{ }^{\circ} \mathrm{C}$ & - \\
5 & "Dynamic" & $40-200{ }^{\circ} \mathrm{C}$ (heating) & $10 \mathrm{~K} / \mathrm{min}$ \\
6 & "Isothermal" & $200{ }^{\circ} \mathrm{C}$ & - \\
7 & "Dynamic" & $200-40{ }^{\circ} \mathrm{C}$ (cooling) & $5 \mathrm{~K} / \mathrm{min}$ \\
8 & "Emergency" & $210{ }^{\circ} \mathrm{C}$ & - \\
\hline
\end{tabular}


temperature of the polypropylene matrix, crystal conversion, crystallinity and half-time of crystallisation temperature (the second segment was supplied to the calculation part).

The crystal conversion was determined on the basis of the crystallization curves, by designation the crystallization enthalpy. Crystallisation enthalpy was determined from the area under the crystallisation curve. On account of curves crystal conversion versus time, the half-time of crystallization was determined as time when crystal conversion achieves $50 \%$. The degree of crystallinity were calculated were calculated as a ratio of the measured $\Delta H$ to the specific heat of fusion of $100 \%$ crystalline polypropylene taken as $290 \mathrm{~J} / \mathrm{g}$.

\section{Results and discussion}

Investigations on polypropylene composites filled with comminuted rapeseed straw conducted so far were focused on the determination of composite mechanical properties [9], on investigations of their dielectric and acoustic properties [25-27] as well as on structural studies carried out with the assistance of the Wide Angle X-ray Scattering (WAXS) method [28]. The objective of the current study was to investigate the nucleation phenomenon occurring during the crystallization process of isotactic polypropylene in lignocellulosic material which was not used until now and which derived from waste rapeseed straw.

Analysis of the influence of rapeseed straw on the crystallization process of isotactic polypropylene

The first investigated parameter was the crystallization temperature of polypropylene. The crystallization temperatures of polypropylenes and polypropylene matrixes in composites were obtained from the maximum of the exothermic peaks. Four polymers were employed which differed considerably with respect to their rheological properties and significantly differing MFR index. As evident from Fig. 1, in the case of polypropylenes characterised by low MFR values (Malen P F-401, Malen P S-702), the presence of filler exerted a significant influence on the crystallization temperature. The unfilled PP1 polypropylene characterised by the lowest MFR index values from among the examined polymers crystallized at the temperature of $115.2{ }^{\circ} \mathrm{C}$, whereas in the composite, it crystallized at the temperature of $119.7^{\circ} \mathrm{C}$. Similar behaviour was recorded in the case of PP2 polypropylene where the difference in the crystallization temperature was also of the order of $4{ }^{\circ} \mathrm{C}$ (crystallization temperatures amounted to 120.9 and $116.9{ }^{\circ} \mathrm{C}$, respectively). On the other hand, in the case of polypropylenes characterised by a high-MFR index,

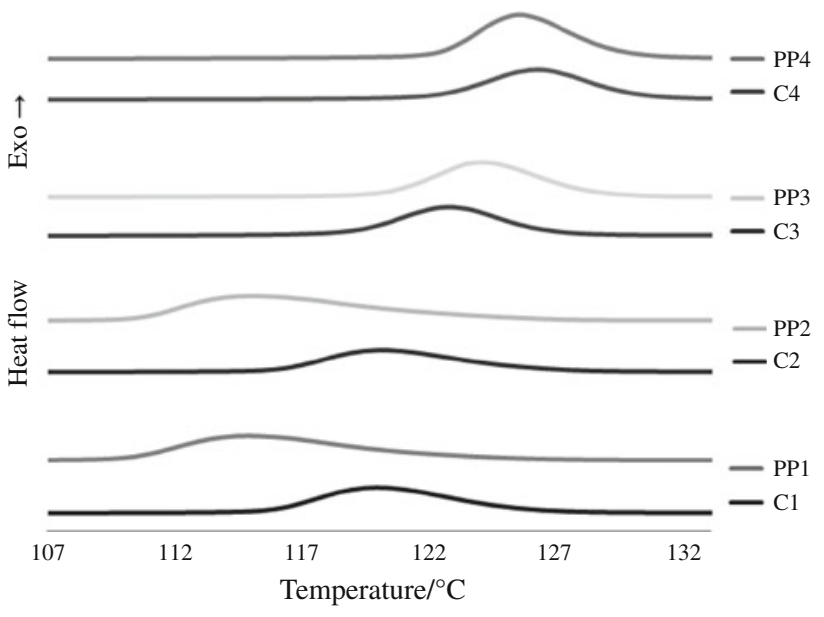

Fig. 1 Influence of rapeseed straw (content $25 \%$ ) on crystallisation temperature for various polypropylene and composites

the presence of the lignocellulosic filler failed to play a significant role and did not change the temperature of polypropylene crystallization. In both cases, differences in crystallization temperatures did not exceed $0.5^{\circ} \mathrm{C}(124.7$ and $124.2^{\circ} \mathrm{C}$ and 125.3 and $125.9^{\circ} \mathrm{C}$, respectively) so it can be said that the presence of lignocellulosic material did not accelerate the crystallization process.

Also half-times of the crystallization temperature for various polypropylenes differing with respect to rheological properties were analysed. Figure 2 shows the comparison of crystallization half-times of unfilled polymers with their composite analogues. It is worth emphasizing the distinct tendency for the shortening of the crystallization half-time of unfilled polypropylenes together with the increase of the MFR index. In the case of composites made up of a matrix composed of just these kinds of polypropylenes, it was observed that in the case of polypropylene characterised by low MFR, the presence of the filler caused a decrease of the crystallization half-time. This drop, in the case of the Malen P F-401 (PP1) polypropylene, amounted

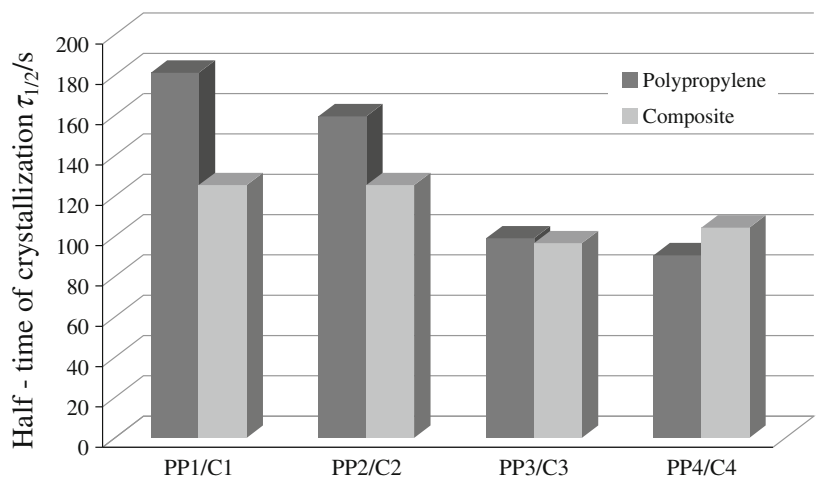

Fig. 2 Influence of rapeseed straw (content $25 \%$ ) on half-time of crystallisation temperature for various polypropylenes and composites 
to $56 \mathrm{~s}$, while in the case of propylene with MFR amounting to 25 and $50 \mathrm{~g} / 10 \mathrm{~min}$ it is evident that the presence of the filler failed to reduce the crystallization half-time (Fig. 2).

This interesting phenomenon is also confirmed by the analysis of the crystal conversion of pure polypropylenes and composite matrices of the same polymers. The results of this comparison are presented in Fig. 3. Differences in the conversion curve runs between unfilled polymers and their composite counterparts are visible for systems with PP1 and PP2. Runs of conversion curves for polymers and composites containing PP3 and PP4 were found to overlap. This means that, in the case of application of polymers of high-MFR index, the presence of lignocellulosic filler does not influence the crystallisation process of the composite matrix.

It is evident that the influence of lignocellulosic materials on the crystallization process of polypropylene matrices is apparent for polymers with relatively low MFR indices only. For polypropylenes with higher MFR values, the values of crystallization temperature and half-time of crystallization in composites were equal in comparison with non-filled polymers.

The observed phenomenon can be attributed to differences in the mobility of polymer chains. The Malen $\mathrm{P}$ S-702 polypropylene differed in its structure from the Malen P F-401 polypropylene in that it had shorter chains. This fact, however, failed to exert a significant impact on the crystallisation process, as evident from the presented diagrams. On the other hand, commercial polymers Moplen HP-548R and Moplen HP-648T contain lowmolecular additives which resulted in a considerably higher MFR index and significantly increased mobility of macromolecules connected with it.

Analysis of the impact of rapeseed straw modification on polypropylene nucleation

Bearing in mind the fact that, most frequently, polypropylenes of low values of the MFR index are used for
Fig. 3 Crystal conversion of polypropylene and composites: a for polypropylene Malen $\mathrm{P}$ F-401, and composite with the matrix of Malen P F-401, b for polypropylene Malen P S-702, and composite with the matrix of Malen P S-702, $\mathbf{c}$ for polypropylene Moplen HP548R, and composite with the matrix of Moplen HP-548R, d for polypropylene Moplen HP-648T, and composite with the matrix of Moplen HP-648T

Fig. 4 Degree of crystallinity for polypropylene (PP1), unmodified and modified composites (content $30 \%$ ) filled various varieties od rapeseed straw (composite I with Bojan variety, composite II with Kaszub variety, composite III with Californium variety, composite IV with Lisek variety)
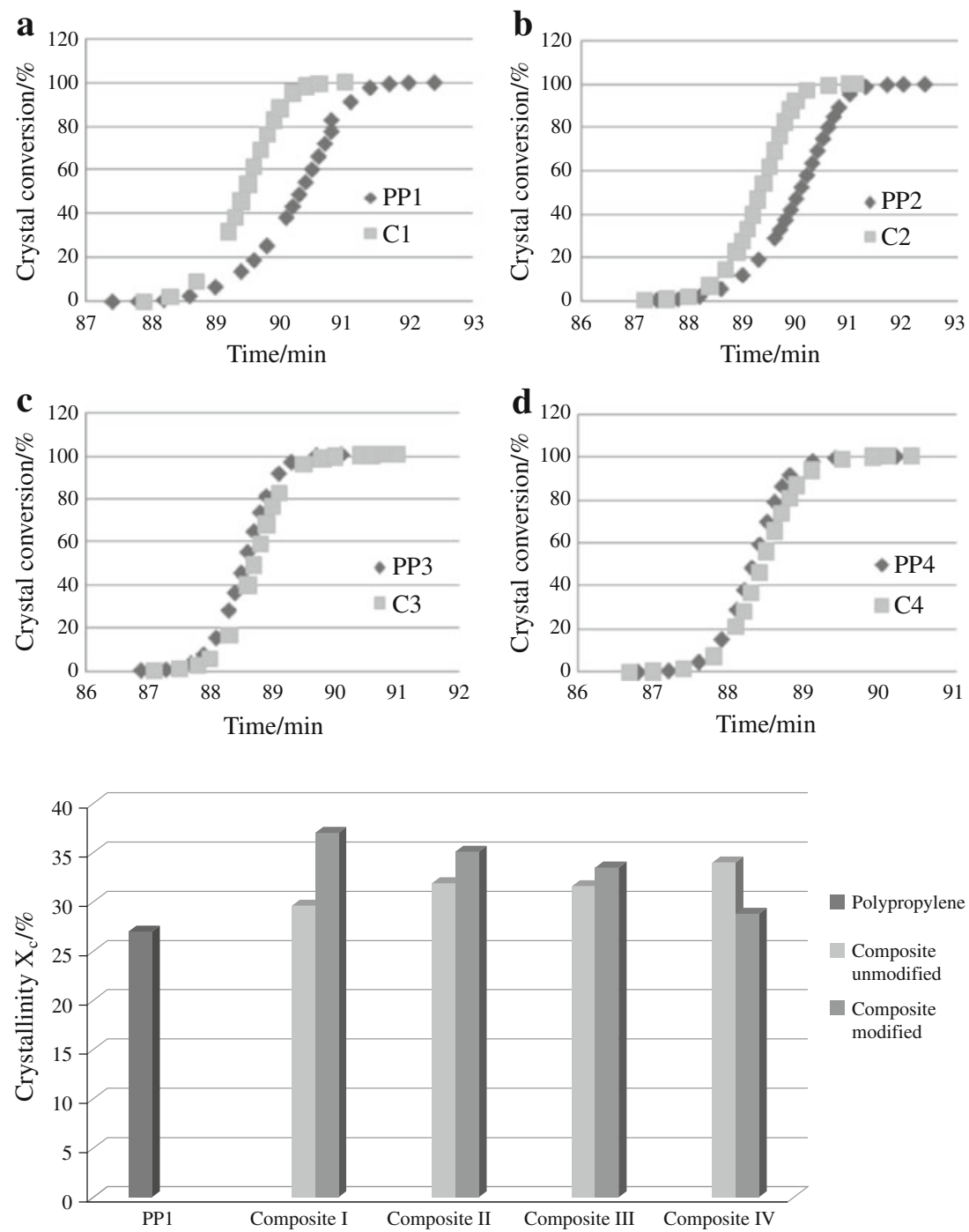
Fig. 5 Influence of the modification of rapeseed straw on crystallization temperature in polypropylene matrix-for Malen P F-401 (PP1) and its composites

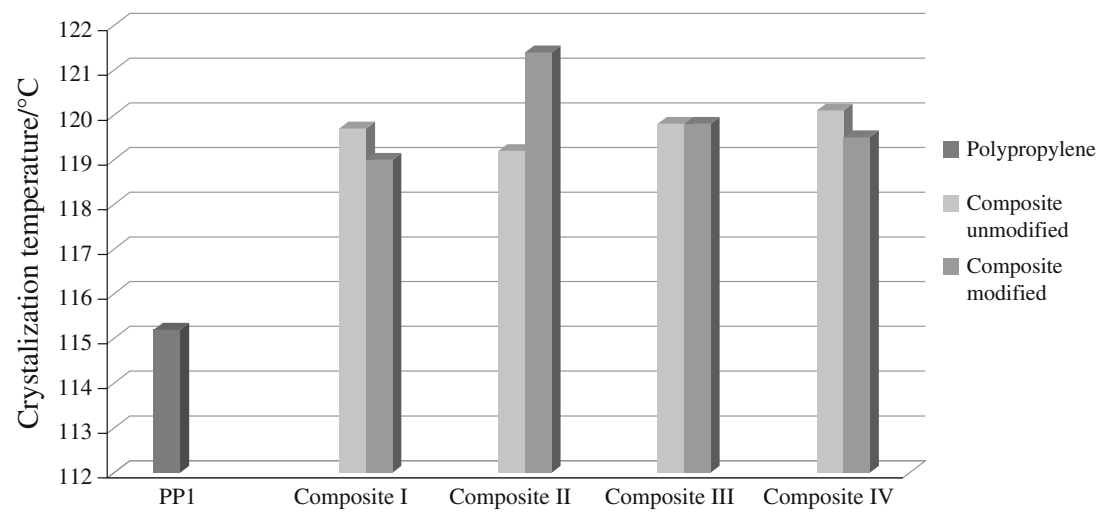

composite production, further experiments were conducted employing a matrix from the Malen P F-401 polypropylene characterised by MFR of 2.4-3.2 g/10 min. Four different varieties of rapeseed straw (Bojan, Californium, Kaszub and Lisek) were used in this series of experiments. The main objective of these investigations was to estimate the influence of rapeseed straw modification on the polypropylene matrix crystallisation process. Another goal was to

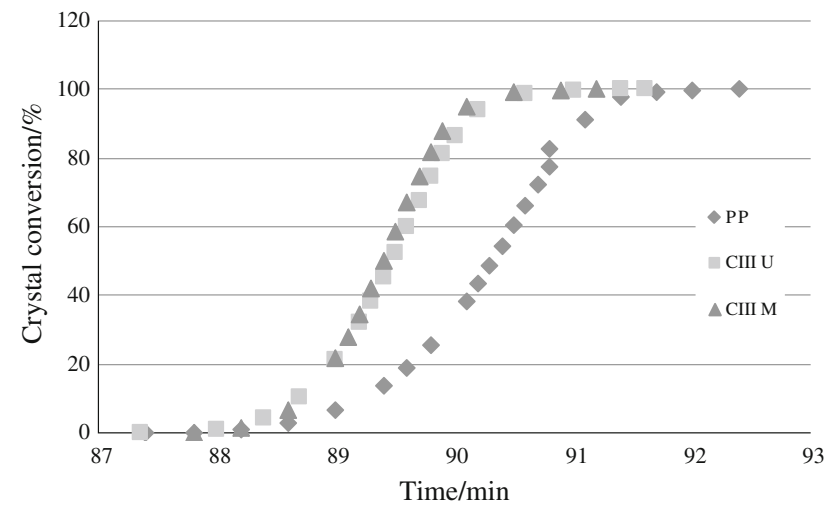

Fig. 6 Crystal conversion of polypropylene Malen P F-401 (PP1), for composite with $30 \%$ of native (unmodified) rapeseed straw of Kaszub variety (CIIIU) and, for composite with $30 \%$ of modified rapeseed straw of Kaszub variety (CIIIM) find out if the variety of rapeseed straw exerted any influence on the polypropylene nucleation process.

It was interesting to analyse the degree of crystallinity of polypropylene and composites. The performed investigations (Fig. 4) demonstrated that differences among composites containing straw from different varieties of rapeseed (for composites with native and modified rapeseed straw) were insignificant. It was further found that the presence of comminuted rapeseed straw affected the degree of crystallinity of the examined samples only slightly.

As demonstrated earlier (Fig. 1), the presence in the composite of the lignocellulosic filler was found to affect the crystallization temperature in the case of polypropylenes of low-MFR index. The consecutive figure shows the dependence of the influence of the chemical modification natural filler on the crystallization temperature of the polypropylene matrix. The applied rapeseed straw modification failed to affect changes in its value as evident from Fig. 5. Crystallization temperatures of the Malen P F-401 propylene containing four different rapeseed straw varieties-irrespective of whether it was native or modified material—changed propylene crystallisation temperature from $115.2{ }^{\circ} \mathrm{C}$ to $119.0-121.4{ }^{\circ} \mathrm{C}$.

The next diagram (Fig. 6) shows crystal conversion for the unfilled Malen P F-401 propylene, for the composite matrix filled with unmodified rapeseed straw of Kaszub
Fig. 7 The half-time of crystallisation of polypropylene Malen P F-401 (PP1) and native and modified composites with rapeseed straw fillers

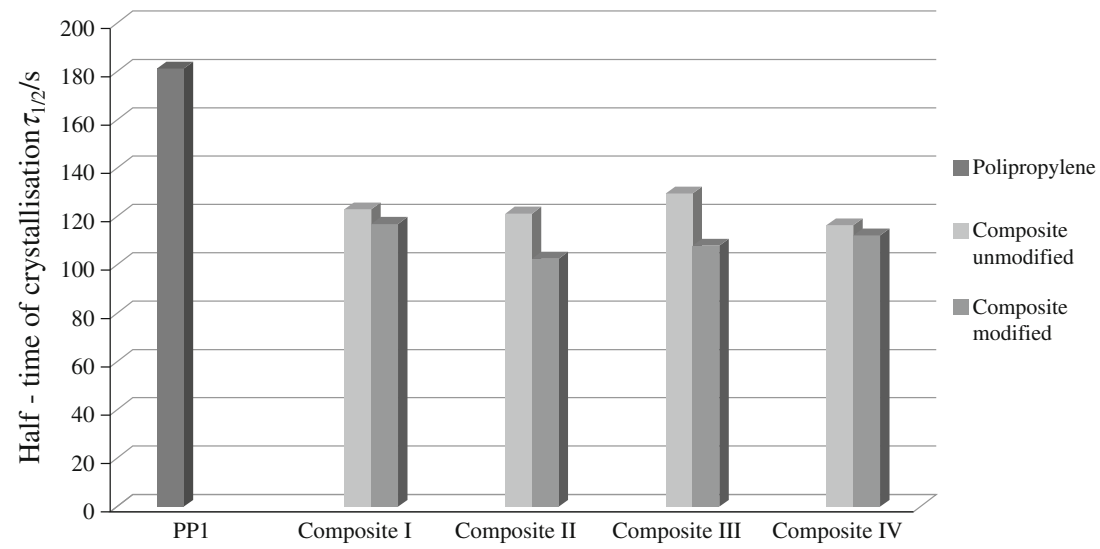


variety and for the composite matrix filled with modified rapeseed straw of the same variety. As evident from Fig. 6, the courses of curves for the matrices of composites containing native and modified rapeseed straw overlap. In the case of the remaining varieties (Bojan, Lisek and Californium), curve crystal conversion runs are identical.

The successive diagram (Fig. 7) presents the dependence of the crystallization half-time of the Malen P F-401 propylene as well as native and modified rapeseed straw of the four examined varieties.

The analysis of the crystal conversion of the polypropylene as a matrix in composites (Fig. 6) confirmed that rapeseed straw modification did not change this parameter of the crystallization process. A similar tendency was observed in the case of changes in the half-time crystallization process.

In the study published by Borysiak [19], two kinds of wood (pine and beech) native and chemically modified (esterified with maleic, propionic, crotonic, succinic and phthalic anhydrides) were used as fillers in polypropylene composites. It was found that the kind of wood used as well as modification of lignocellulosic materials failed to change significantly the crystallization temperature of the polypropylene. A strong increase of the crystallization temperature by $5-9{ }^{\circ} \mathrm{C}$ was found in unmodified and modified wood composites in comparison with pure polypropylene (Malen p F-401) [19]. In the case of the rapeseed straw, this difference was only slightly smaller suggesting that pine wood, beech wood as well as rapeseed straw acted as heterogeneous nucleants for propylene.

Borysiak [19] found that composites containing chemically treated wood fillers showed a tendency towards reduction of polypropylene efficiency. Such dependence was not recorded in the course of investigations carried out within the framework of this research project. The observed differences can be attributed, primarily, to the difference between various fillers as well as to the kind of chemical modification of surface lignocellulosic materials. Moreover, in the presence of chemically modified wood, values of the crystallization temperature of polypropylene were by about $1-4{ }^{\circ} \mathrm{C}$ higher. As in the case referred to earlier, investigations carried out on a different lignocellulosic material such as comminuted rapeseed straw revealed dissimilarity with regard to investigations performed on polypropylene composites containing different wood species.

\section{Conclusions}

The following conclusions can be drawn on the basis of the obtained research results:
- It was found that both native as well as chemically modified rapeseed straw served an active crystallization nucleants of isotactic polypropylene characterised by low values of the MFR index.

- It was observed that for polypropylenes with high-MFR values, the values of crystallization temperatures and crystallization half-times in the composites were identical in comparison with non-filled polymers.

- A correlation was found between the MFR index and temperature of polypropylene crystallization.

- The analysis of the crystallization temperature confirmed that the modification of rapeseed straw did not change this parameter of the crystallization process. A similar tendency was observed in case of changes in the half-time crystallization process.

- The analysis of temperatures and half-times of crystallization showed that the presence of lignified particles of rapeseed straw in the composite exerted an important influence on crystallization conditions.

- No significant differences were determined between the effect of different varieties of rapeseed straw on the nucleation of isotactic polypropylene both in the case of the application of native and modified straw. This means that the application of various varieties of rapeseed straw did not exert a significant impact on composite properties.

The research results presented in this paper do not only expand our knowledge about the nucleation effect of a lignocellulosic material, i.e. comminuted rapeseed straw, which has not been used so far but also offer novel technological solutions for industrial production of isotactic polypropylene composites. New technological solutions can be associated with production of continuous profiles with the assistance of the extrusion technique (e.g. floor slats or board-like articles to be applied for terrace cover) or for the production of various articles with the assistance of injection moulding (e.g. toys, containers or details used in motor and furniture industries).

Acknowledgements This study was supported by Grant of Polish National Science Centre no. 32-6190/2011-2013.

Open Access This article is distributed under the terms of the Creative Commons Attribution License which permits any use, distribution, and reproduction in any medium, provided the original author(s) and the source are credited.

\section{References}

1. Błędzki AK, Gassan J. Composites reinforced with cellulose based fibres. Prog Polym Sci. 1999;24(2):221-74.

2. Karimi AN, Tajvidi M, Pourabbasi S. Effect of compatibilizer on the natural durability of wood flour/high density polyethylene 
composites against rainbow fungus (Coriolus versicolor). Polym Compos. 2007;28(3):273-7.

3. Yang HS, Wolcott MP, Kim HS, Kim S, Kim HJ. Properties of lignocellulosic material filled polypropylene bio-composites made with different manufacturing processes. Polym Test. 2006; 25(5):668-76

4. Shubhra QTH, Alam AKMM, Gafur MA, Shamsuddin SM, Khan SM, Saha M, Saha D, Quaiyyum MAJA, Khan JA, Ashaduzzaman MD. Characterization of plant and animal based natural fibers reinforced polypropylene composites and their comparative study. Fibres Polym. 2010;11:725-31.

5. Butylina S, Martikka O, Kärki T. Properties of wood fibrepolypropylene composites: effect of wood fibre source. Apel Campos Mater. 2011;18(2):101-11.

6. Borysiak S, Paukszta D, Batkowska P,. Mankowski J. The structure, morphology, and mechanical properties of thermoplastic composites with lignocellulosic fiber. In: Cellulose fibers: bio- and nano-polymer composites. Berlin: Springer; 2011. p. 263-90.

7. Paukszta D. Investigations of lignocellulositc materials from rape for the purpose of producing composites with thermoplastic polymers. Fibres Text East Eur. 2005;13(2):90-2.

8. Borysiak S, Garbarczyk J, Kozlowski R, Mankowski J, Paukszta D. Patent of Poland, no.202219. Sposób otrzymywania kompozytu poprzez łạczenie polimerów termoplastycznych oraz słomy rzepakowej (Metod of prepration of composites by joining thermoplastic polymers with the straw of oilseed rape). Submitted on 30 Dec 2002 (P 358038), obtained on 16 July 2009.

9. Borysiak S, Paukszta D. Mechanical properties of lignocellulosic/ polypropylene composites. Mol Cryst Liq Cryst. 2008;484:37988.

10. Binsbergen FL. Heterogeneous nucleation in the crystallization of polyolefins: part 1 . Chemical and physical nature of nucleating agents. Polymer. 1970;11(5):253-67.

11. Wunderlich B. Macromolecular physics, vol II. New York: Academic Press; 1976.

12. Chatterjee AM, Price FM, Newman SJ. J Pol Sci Pol Phys Ed. 1975;13:2369-84.

13. Chatterjee AM, Price FM, Newman SJ. J Pol Sci Pol Phys Ed. 1975;13:2385-90.
14. Chatterjee AM, Price FM, Newman SJ. J Pol Sci Pol Phys Ed. 1975;13:2391-8.

15. Mencel J, Varga J. J Thermal Anal. 1983;28:161-74.

16. Bogoeva-Gaceva G, Janevski A, Mader E. Nucleaction activity of glass fibers towards iPP evaluated by DSC and polarizing light microscopy. Polymers. 2001;42(9):4409-16.

17. Mucha M, Krolikowski Z. The effect of fillers on crystallization kinetics of polypropylene. J Therm Anal Calorim. 2003;74(2): 549-57.

18. Jikan SS, Ariff ZM, Ariffin A. J Therm Anal Calorim. 2010;102: 1011-7.

19. Borysiak S. Determination of nucleating ability of wood for nonisothermal crystallization of polypropylene. J Therm Anal Calorim. 2007;88(2):455-62.

20. Borysiak S. A study of transcrystallinity in polypropylene in the presence of wood irradiated with $\gamma$ rays. J Therm Anal Calorim. 2010;101:439-45.

21. Bouza R, Marco C, Martin Z, Gómez MA, Barral L. Dynamic crystallization of polypropylene and wood-based composites. J Appl Pol Sci. 2006;102(6):6028-36.

22. Bouza R, Marco C, Eblis G, Martin Z, Gómez MA, Barral L. Analysis of the isothermal crystallization of polypropylene/wood flour composites. J Therm Anal Calorim. 2008;94(1):119-27.

23. Błędzki AK, Reihmane S, Gassan J. Properties and modification methods for vegetable fibers for natural fiber composites. J Appl Pol Sci. 1996;59(8):1329-36.

24. Joseph PV, Joseph K, Thomas S, Pillai CKS, Prasad VS, Groeninckx G, Sarkissova M. The thermal and crystallisation studies of short sisal fibre reinforced polypropylene composites. J Compos A. 2003;34:253-66.

25. Markiewicz E, Borysiak S, Paukszta D. Polypropylene-lignocellulosic material composites as promising sound absorbing materials. Polymers. 2009;54(6):430-5.

26. Markiewicz E, Paukszta D, Borysiak S. Dielectric properties of lignocellulosic materials-polypropylene composites. Mater SciPoland. 2009;27(2):581-94.

27. Markiewicz E, Paukszta D, Borysiak S. Acoustic and dielectric properties of polypropylene lignocellulosic materials composites. In: Polypropylene. Rijeka: Editorial Board; 2011 (in press).

28. Paukszta D. (in press). 